\title{
PALINOESTRATIGRAFIA DA FORMAÇÃO SOLIMÕES NA REGIÃO DO ALTO SOLIMÕES (ATALAIA DO NORTE E TABATINGA), AMAZONAS, BRASIL
}

\author{
Rosemery Rocha da SILVEIRA ${ }^{1,2}$ \& Paulo A. SOUZA ${ }^{2}$
}

(1) Departamento de Geologia, Instituto de Ciências Exatas, Universidade Federal do Amazonas. Av. General Rodrigo Jordão Ramos, 3000, CEP 69077-000, Manaus, AM, Brasil. Endereço eletrônico: rrsilveira@ufam.edu.br

(2) Programa de Pós-Graduação em Geociências, Laboratório de Palinologia Marleni Marques Toigo, Instituto de Geociências, Universidade Federal do Rio Grande do Sul. Av. Bento Gonçalves, 9500, CEP 91540-000, Porto Alegre, RS, Brasil. Endereço eletrônico: paulo.alves.souza@ufrgs.br

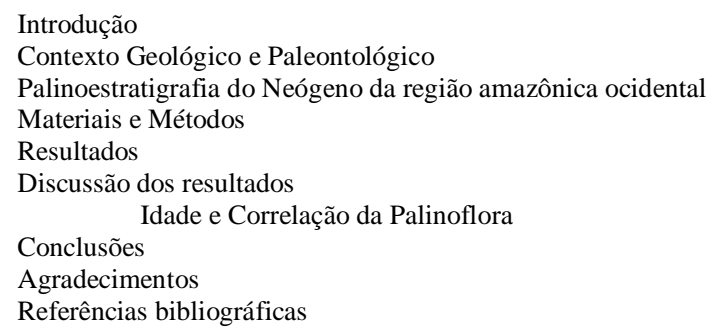

RESUMO - Este trabalho apresenta os resultados palinoestratigráficos de sete seções de superfície da Formação Solimões, Bacia do Solimões, em áreas adjacentes aos municípios de Atalaia do Norte e Tabatinga, Estado do Amazonas, ocorrentes às margens dos rios Solimões e Javari, bem como da rodovia BR307. Um total de 44 amostras foi analisado, resultando em conjuntos palinológicos relativamente abundantes e diversificados, compostos por 57 táxons de palinomorfos: 7 espécies de algas clorofíceas, 1 de alga dinofícea, 13 de esporos de pteridófitas, 2 de grãos de pólen de gimnospermas e 34 de grãos de pólen de angiospermas. Espécies guia de zoneamentos palinológicos previamente propostos foram reconhecidos, incluindo espécies de esporos (Crassoretitriletes vanraadshooveni, Foveotriletes ornatos), de grãos de pólen (Grimsdalea magnaclavata, Multimarginites vanderhammeni, Perfotricolpites digitatus, Bombacacidites baculatus, Psilastephanoporites tesseroporus, Jandufouria seamrogiformis e Psilatricolporites caribbiensis) e de dinoflagelado (Diphyes sp.). A associação dessas formas permitiu posicionar os depósitos superficiais da Formação Solimões na região de Tabatinga e Atalaia do Norte no Mioceno médio-Plioceno.

Palavras-chave: Palinoestratigrafia, Neogeno, Formação Solimões.

\begin{abstract}
This paper presents the palynostratigraphic results obtained from seven surface sections of the Solimões Formation (Solimões Basin), in adjacent areas of the Atalaia do Norte and Tabatinga municipalities, Amazonas State, at the Solimões and Javari riverbanks, as well as from the BR307 road. A total of 44 samples was analyzed revealing abundant and diverse palynological assemblages, comprising 57 taxa of palynomorphs concerning species of chlorophycean (7) and dinophycean (1) algae, pteridophyte spores (13), and gimnosperm (2) angiosperm (34) pollen grains. Guide species of zonal schemes previously proposed were recognized, including spores (Crassoretitriletes vanraadshooveni, Foveotriletes ornatos), pollen grains (Grimsdalea magnaclavata, Multimarginites vanderhammeni, Perfotricolpites digitatus, Bombacacidites baculatus, Psilastephanoporites tesseroporus, Jandufouria seamrogiformis and Psilatricolporites caribbieneis) and dinocyst (Diphyes sp.).These taxa indicate an age assignment in the middle Miocene-Pliocene.
\end{abstract}

Keywords: Palynostratigraphy, Neogene, Solimões Formation.

\section{INTRODUÇÃO}

Palinomorfos de natureza terrestre e marinha são amplamente utilizados para a determinação de paleoambientes, idades e correlações em várias bacias sedimentares brasileiras, constituindo ferramenta significativa na resolução de problemas geológicos. A história evolutiva da floresta amazônica tem sido interpretada a partir de levantamentos paleoflorísticos, com destaque para os estudos palinológicos, em sua maioria oriundos da região central (Cruz, 1984) e ocidental (Hoorn, 1993; Leite, 2006; Silva-Caminha et al., 2010; Leandro, 2012).
A Formação Solimões é uma unidade rica em fósseis, com relativa abundância de palinomorfos, permitindo contribuições em termos paleoambientais e bioestratigráficos. Nos últimos anos, trabalhos de detalhe têm permitido aprimoramentos nestes temas, principalmente quando apoiados por controle estratigráfico da amostragem e integração com dados de natureza geológica, tal como verificado em Silveira (2005), Silveira \& Nogueira (2007), Dino et al. (2012), Nogueira et al. (2013), Guimarães et al. (2015) e Soares et al. (2015).

Para Cruz (1984), os depósitos da Formação Solimões, na porção central da Amazônia, 
correspondem a idades entre Eomioceno ao Plioceno. Hoorn (1993) verificou palinozonas na unidade que abrangem todo o Mioceno. Trabalhos mais recentes, nas proximidades dos testemunhos estudados por Hoorn (1993) apontam para idades que variam de Mioceno Inferior ao Plioceno (Leite, 2006; SilvaCaminha et al., 2010). Estas observações implicam que a unidade tem idade variável de acordo com a área de amostragem, sendo imprescindível a delimitação da distribuição dos corpos ao longo da bacia e suas idades particulares, de modo a evitar generalizações. Este trabalho apresenta os resultados de estudos palinoestratigráficos de superfície de sete seções de superfície em áreas adjacentes aos municípios de Atalaia do Norte e Tabatinga, no Estado do Amazonas, ocorrentes às margens dos rios Solimões e Javari, bem como da rodovia BR307. Dados sobre os palinomorfos registrados nestas localidades já foram divulgados em Silveira (2015) e em Silveira \& Souza (2015, 2016).

\section{CONTEXTO GEOLÓGICO E PALEONTOLÓGICO}

Dentre as bacias intracratônicas brasileiras, a Bacia do Solimões é a mais importante em termos de exploração de hidrocarbonetos, oriundos de depósitos paleozoicos. A bacia apresenta, grosso modo, orientação leste-oeste, tendo se desenvolvido sobre rochas cristalinas e sedimentares proterozoicas da Província Amazônia Central, e se encontra compartimentada pelo Arco intra-bacial Carauari nas sub-bacias de Jandiatuba e Juruá. A leste é limitada pelo Arco de Purus, com a Bacia do Amazonas; a oeste é separada, pelo Arco de Iquitos, das bacias subandinas; a sul, limita-se com o Escudo Brasileiro e a norte pelo Escudo das Guianas (Caputo, 1984; Eiras et al., 1994; Wanderley Filho et al., 2007) (figura 1A).

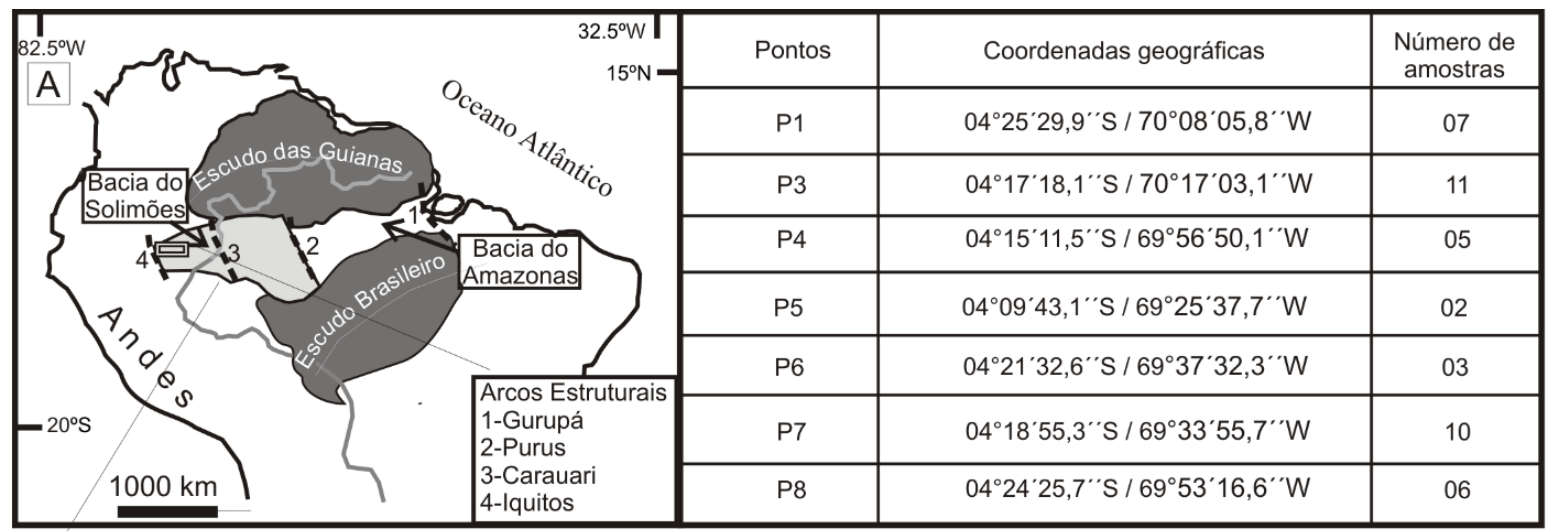

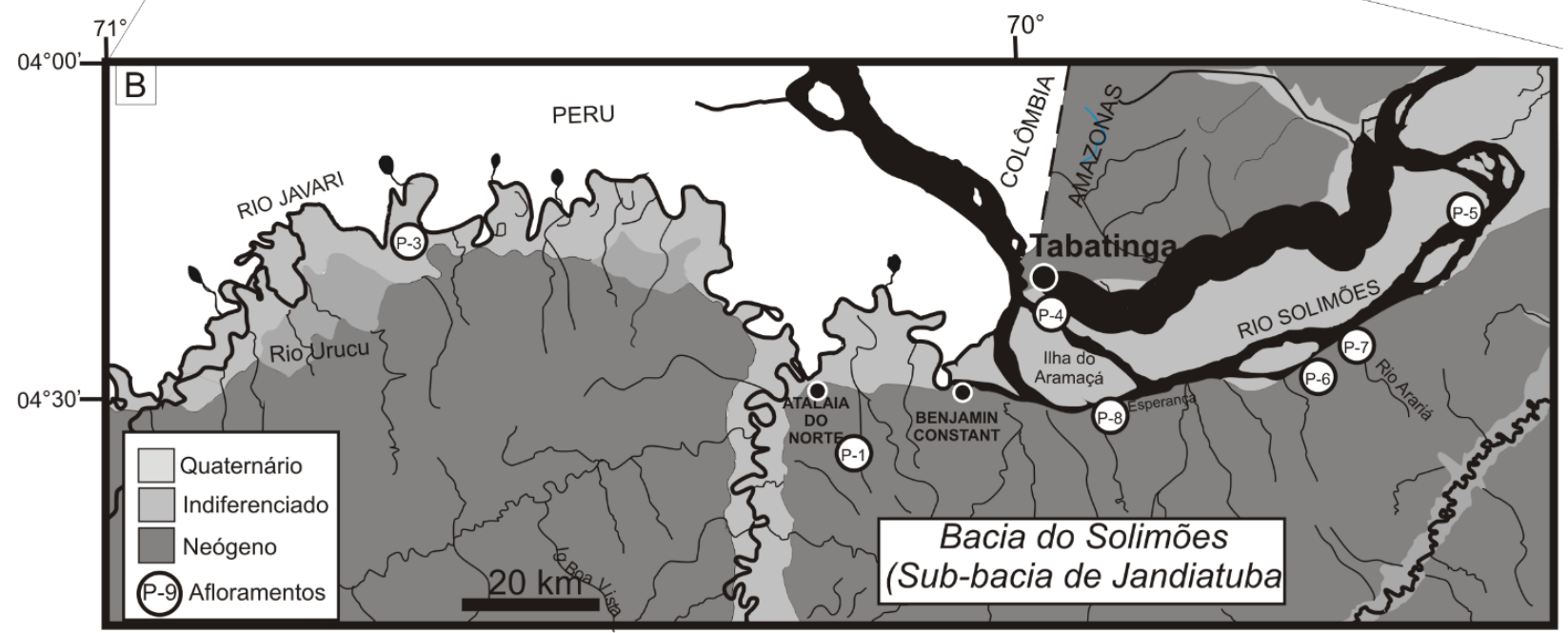

Figura 1. Localização da área de amostragem: Mapa geológico (A) e dos pontos de coleta na Sub-bacia do Jandiatuba, Bacia do Solimões (B). 
O registro sedimentar da Bacia do Solimões é marcado por múltiplos eventos de regressão e transgressão marinhas vinculados aos processos de subsidência e soerguimento, relacionados ao comportamento dos arcos estruturais ativos, principalmente durante o Paleozoico (Caputo \& Silva, 1991). O Arco de Carauari teve controle decisivo na distribuição e espessura das sucessões sedimentares, particularmente até o Pennsilvaniano e, provavelmente, influenciou a deposição das unidades sedimentares do Cretáceo Superior e do Neógeno (Eiras et al., 1994).

A última sequência deposicional da bacia corresponde ao Grupo Javari, compreendendo rochas relacionadas aos intervalos Alagoas (Aptiano) até Cenomaniano (Dino et al., (1999), correspondente à Formação Alter do Chão, que é separada por discordância erosiva da Formação Solimões, do Mioceno-Plioceno (Eiras et al., 1994; Cunha et al., 2007). Terraços fluviais mais jovens, do Quaternário, recobrem localmente a unidades.

Dentre as unidades neógenas, a Formação Solimões apresenta grande distribuição espacial, ocorrendo em porção restrita da Bacia do Amazonas, e ampla nas bacias do Acre e Solimões. Fora da Amazônia brasileira, ocorre também na Amazônia colombiana e peruana, onde recebe os nomes de "Terciário Amazônico" e Formação Pebas, respectivamente (Hoorn, 1993, 1994).

O nome "Série Solimões" foi primeiramente utilizado por Moraes-Rego (1930) para designar a seção cenozoica argilosa exposta ao longo do rio Solimões. Caputo et al. (1971) e o relatório do Projeto RADAMBRASIL (Brasil, 1978) correlacionaram esta seção com as bacias subandinas, revalidando a unidade como Formação Solimões.

No que concerne aos dados paleontológicos, a Formação Solimões, na Sub-bacia do Jandiatuba, apresenta grande diversidade fossilífera, incluindo microfósseis, megafósseis vegetais, invertebrados e vertebrados, com conteúdo muito semelhante ao das bacias subandinas e Bacia do Acre (Latrubesse et al., 2007, 2010). A maioria dos trabalhos palinológicos da Formação Solimões é advinda de seções de subsuperfície dos estados do Amazonas (Cruz, 1984; Hoorn, 1993; Leite, 2006; Silva-Caminha et al., 2010) e de superfície do Acre (Latrubesse et al., 2007). Silveira (2005) foi quem primeiro registrou palinomorfos em seções aflorantes do estado do Amazonas, correspondentes à localidade de Coari, com detalhamento em Silveira \& Nogueira (2007), Nogueira et al. (2013) e Guimarães et al. (2013). Microfósseis calcários estão presentes, referentes a ostracodes (Purper, 1979; Purper \& Ornellas, 1991; Ramos, 2006; Wesselingh \& Ramos, 2010). Restos vegetais fósseis foram também documentados na unidade em território brasileiro (Silveira, 2005; Silveira \& Nogueira, 2007), contudo ainda não foram adequadamente estudados. Os moluscos se acham representados na unidade por gastrópodes e bivalves (Nuttall, 1990; Vonhof et al., 1998; Wesselingh et al., 2002). Vertebrados fósseis são os organismos mais estudados na Formação Solimões, encontrados nos estados do Acre e Amazonas, referentes a peixes, aves, répteis e mamíferos, conforme sintetizado em Latrubesse et al. (2007, 2010).

Na Sub-bacia do Juruá, a Formação Solimões tem sua representação paleontológica limitada a vegetais, tais como folhas, troncos e esporomorfos (Brasil, 1978; Cruz, 1984; Arai et al., 2003; Silveira, 2005; Silveira \& Nogueira, 2007; Nogueira et al., 2013; Guimarães et al., 2013).

A idade da Formação Solimões, estabelecida a partir de estudos palinológicos, foi primeiramente proposta por Daemon \& Contreiras (1971), que posicionaram a unidade entre o Paleoceno e o Pleistoceno. Cruz (1984) admitiu, para a unidade na porção central da Amazônia, uma idade entre Mioceno inferior ao Plioceno. As análises palinológicas de Hoorn (1993) compreendem seções entre Mioceno inferior e o limite Mioceno médio/superior, segundo a cronoestratigrafia corroborada por Arai et al. (2003). Trabalhos mais recentes, desenvolvidos nas porções central e ocidental da Amazônia brasileira (Silveira, 2005; Silveira \& Nogueira, 2007; Leite, 2006; Silva-Caminha et al., 2010), apontam idades compatíveis com aquela estabelecida por Cruz (1984). 


\section{PALINOESTRATIGRAFIA DO NEÓGENO DA REGIÃO AMAZÔNICA OCIDENTAL}

Importantes zoneamentos bioestratigráficos foram realizados para a porção norte da América do Sul, comumente empregados para a determinação de idades relativas dos depósitos mesozoicos e cenozoicos (Germeraad et al., 1968; Daemon \& Contreiras, 1971; Regali, 1971; Regali et al., 1974a,b; Lorente, 1986; Muller et al., 1987), enquanto outros são relacionados especificamente ao Neogeno da Amazônia brasileira (Cruz, 1984; Hoorn, 1993; Leite, 2006; Silva-Caminha et al., 2010).

No zoneamento proposto por Cruz (1984) nas áreas mais ocidentais da Amazônia, foram reconhecidas três zonas palinológicas na Formação Solimões, denominadas: Zona A (Mioceno), Zona B (passagem do Mioceno a Plioceno) e Zona C (Plioceno). Para a Venezuela, Lorente (1986) propôs sete zonas correspondentes ao Neógeno: Zona de intervalo de Cicatricosisporites, Zona Verrutricolporites (ambas relacionadas ao Mioceno inferior), Zona Psiladiporites (Mioceno inferior ao médio mais basal), Zona Crassoretitriletes (Mioceno médio), Zona Grimsdalea (Mioceno médio à base do superior), Zona Asteraceae (Mioceno superior) e Zona Fenestrites longispinosus (Mioceno superior a Plioceno). Este zoneamento encontra correspondência com esquemas bioestratigráficos registrados na Formação Solimões em território brasileiro (Hoorn, 1993; Leite, 2008; Silva-Caminha et al., 2010), dentre os quais o de Hoorn (1993) apresenta maior similaridade com os depósitos da faixa aflorantes de Atalaia do Norte e Tabatinga.

O material estudado por Hoorn (1993) é referente a amostras de subsuperfície no Estado do Amazonas, nas quais foram caracterizadas cinco zonas, sintetizadas, da base para o topo, como segue. A Zona de Acme de Verrutricolporites é definida pela abundância de Verrutricolporites rotundisporus, que diminui quantitativamente no topo da zona (Aquitaniano - Burdigaliano inferior). A Zona de Acme de Retitricolporites é marcada pela abundância de Retitricolporites guaianensis; sua base é definida pelo rápido decréscimo de Verrutricolporites rotundisporus, e topo caracterizado pelo aparecimento da associação Psiladiporites-Crototricolpites, com idade atribuída ao Burdigaliano inicial a Burdigaliano final. A Zona de Concorrência PsiladiporitesCrototricolpites (Burdigaliano superior - base do Langhiano superior) é caracterizada pela concorrência dessas espécies a partir da base da zona, com topo da zona marcado pelo primeiro aparecimento de Crassoretitriletes vanraadshooveni. A base da Zona de Intervalo de Crassoretitriletes (Langhiano superior a Serravaliano superior) é marcada pelo aparecimento de Crassoretitriletes vanraadshooveni e topo pelo aparecimento de Grimsdalea magnaclavata. Por último, a Zona de Intervalo de Grimsdalea (Serravaliano superior a Tortoniano médio) tem base marcada pela ocorrência de Grimsdalea magnaclavata, sendo o topo indefinido, marcado pelo limite superior da amostragem.

Lorente (1986) já havia apresentado essas zonas para bacias da Venezuela, e definiu ainda zonas mais jovens, como: zonas Asteraceaea (Mioceno superior), Fenestrites longispinosus e Alnipollenites. A Zona Fenestrites longispinosus foi ainda subdividida em Stephanocolpites evansii (Mioceno superior), Psilatricolporites caribbiensis (Plioceno inferior-médio)

Echitricolporites/Alnipollenites (Plioceno superior).

Os zoneamentos apresentados posteriormente (Leite, 2006; Silva-Caminha et al., 2010; Leandro, 2012) tem relação com zonas mais jovens que as de Hoorn (1993), e assumidas como contemporâneas às zonas propostas por Lorente (1986). Os resultados de Jaramillo et al. (2011), a partir de estudo realizado na Colômbia, mostram uma inversão na distribuição estratigráfica de determinadas espécies guias, não compatível com os zoneamentos propostos para a Amazônia brasileira, mas aceitos por Soares et al. (2015).

\section{MATERIAIS E MÉTODOS}

Ao longo de margens de rios Javari e Solimões foram investigados sete afloramentos, nomeados de P1, P3, P4, P5, P6, P7 e P8, e um corte de estrada na rodovia BR-307 
(denominado P1) que liga os municípios de Benjamin Constant e Atalaia do Norte (figura 1B), no período de vazante dos rios (novembro de 2009). Perfis estratigráficos foram confeccionados em cada exposição (figura 2), ressaltando as características litológicas e os níveis amostrados, correspondentes a litologias com coloração cinza escuro. Destas sete seções, 44 amostras foram selecionadas para processamento e análise palinológica. O processamento inicial, envolvendo as fases de secagem, pesagem e trituração, foi realizado no Laboratório de Paleontologia da Universidade Federal do Amazonas. O tratamento químico, para separação e concentração da matéria orgânica particulada por meio da dissolução dos carbonatos (com $\mathrm{HCl})$ e silicatos (com HF) foi realizado no Laboratório de Palinologia Marleni Marques Toigo, do Instituto de Geociências da Universidade Federal do Rio Grande do Sul (LPMMT-UFRGS), conforme sintetizado em Silva et al. (2011). Os resíduos finais foram obtidos por peneiramento, concentrando-se a fração maior que $10 \mu \mathrm{m}$, permitindo a confecção de 129 lâminas (duas a quatro lâminas por amostra). Todas as lâminas estão depositadas na Palinoteca do LPMMT-UFRGS sob codificação e números MP-P 6764 a 6788, 7492 a 7755 e 10115 a 10158.

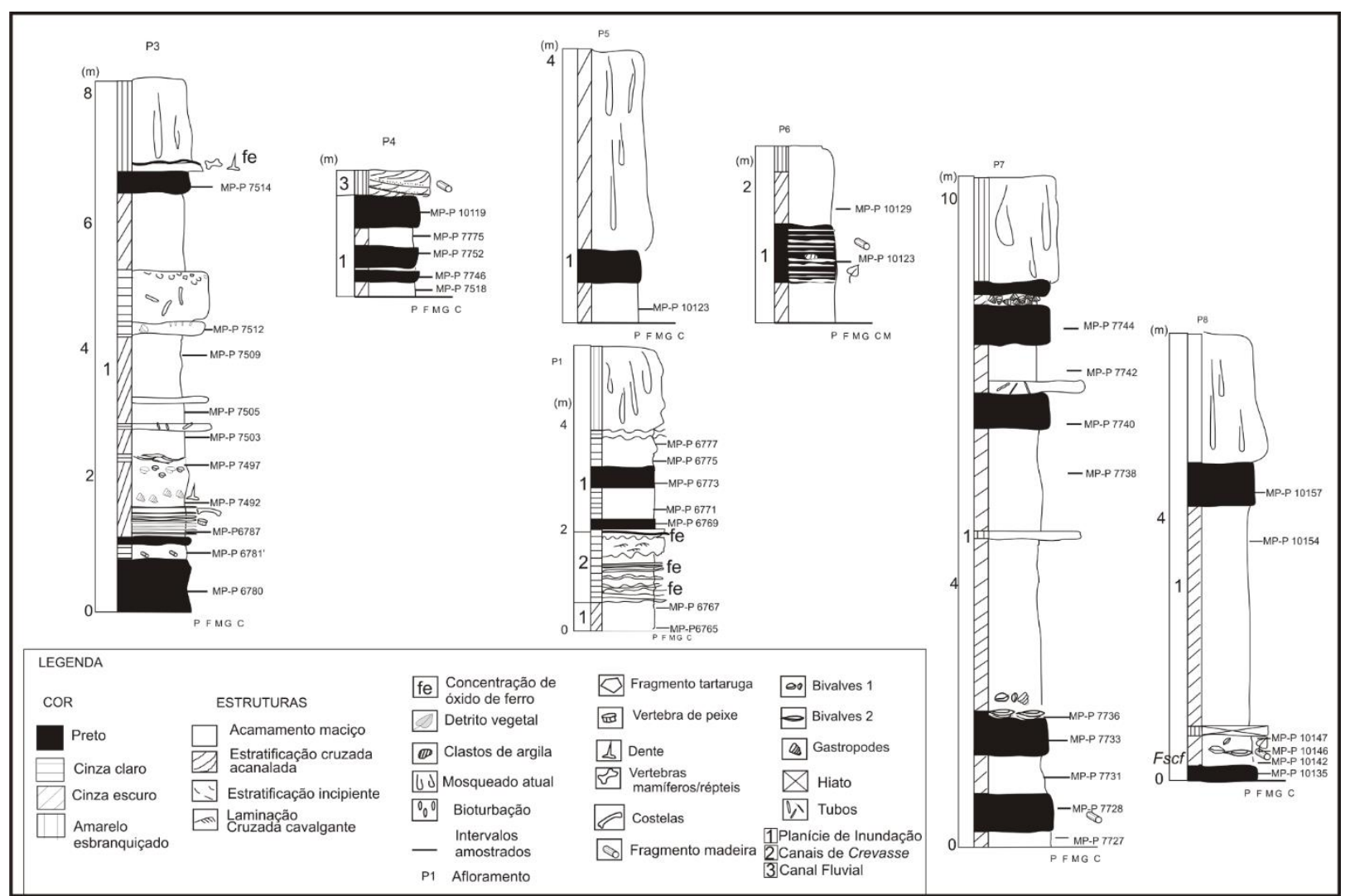

Figura 2. Perfis estratigráficos adquiridos para a região de Atalaia do Norte a Tabatinga, porção ocidental da Amazônia brasileira.

\section{RESULTADOS}

A grande maioria dos níveis amostrados apresentou-se fértil, com conjuntos palinológicos diversificados e abundantes, compostos de palinomorfos. Um total de 57 táxons de palinomorfos foi reconhecido no estudo palinotaxonômico, correspondentes a 7 espécies de algas clorofíceas, 1 de alga dinofícea, 13 de esporos de pteridófitas, 2 de grãos de pólen de gimnospermas e 34 de grãos de pólen de angiospermas. Além disso, esporos de fungos foram registrados, embora não tenham sido quantificados ou reconhecidos. A lista completa dos táxons com a respectiva base nomenclatural é apresentada no quadro 1. Descrições e ilustrações da maioria dos palinomorfos registrados nestas localidades foram divulgados em Silveira (2015) e em Silveira \& Souza $(2015,2016)$. 
De modo geral, os palinomorfos apresentam excelente estágio de preservação, raramente ocorrendo rasgados ou corroídos, sendo comum o registro de tétrades e políades, principalmente das espécies Deltoidospora adriennis e Monoporites annulatus e, subordinadamente, representantes do gênero Bombacacidites.

A distribuição estratigráfica dos táxons é apresentada por localidade nas figuras 3 a 8 . Dentre os esporomorfos, alguns têm maior representação, com documentação em todos os afloramentos e na maioria dos níveis amostrados, tais como Deltoidospora adriennis, Crassoretitriletes vanraadshooveni, Magnastritites grandiosus, Verrucatosporites usmensis, Bombacacidites nacimientoensis e Grimsdalea magnaclavata. De modo geral as algas clorofíceas e dinofícea ocorrem de forma subordinada, com destaque quantitativo restrito em determinados níveis estratigráficos.

Considerando zoneamentos palinoestratigráficos estabelecidos para o mesmo intervalo de tempo para a porção norte da América do Sul, verifica-se que alguns dos táxons apresentam distribuição estratigráfica ampla, tais como Cyathidites spp., Deltoidospora adriennis, Kuylisporites waterbolkii, Polypodiaceoisporites potoniei, Monoporites annulatus, Mauritiidites franciscoi, Magnastriatites grandiosus, Echiperiporites estelae, Retitricolporites irregularis e Verrucatosporites usmensis, não contribuindo para a determinação de idade.

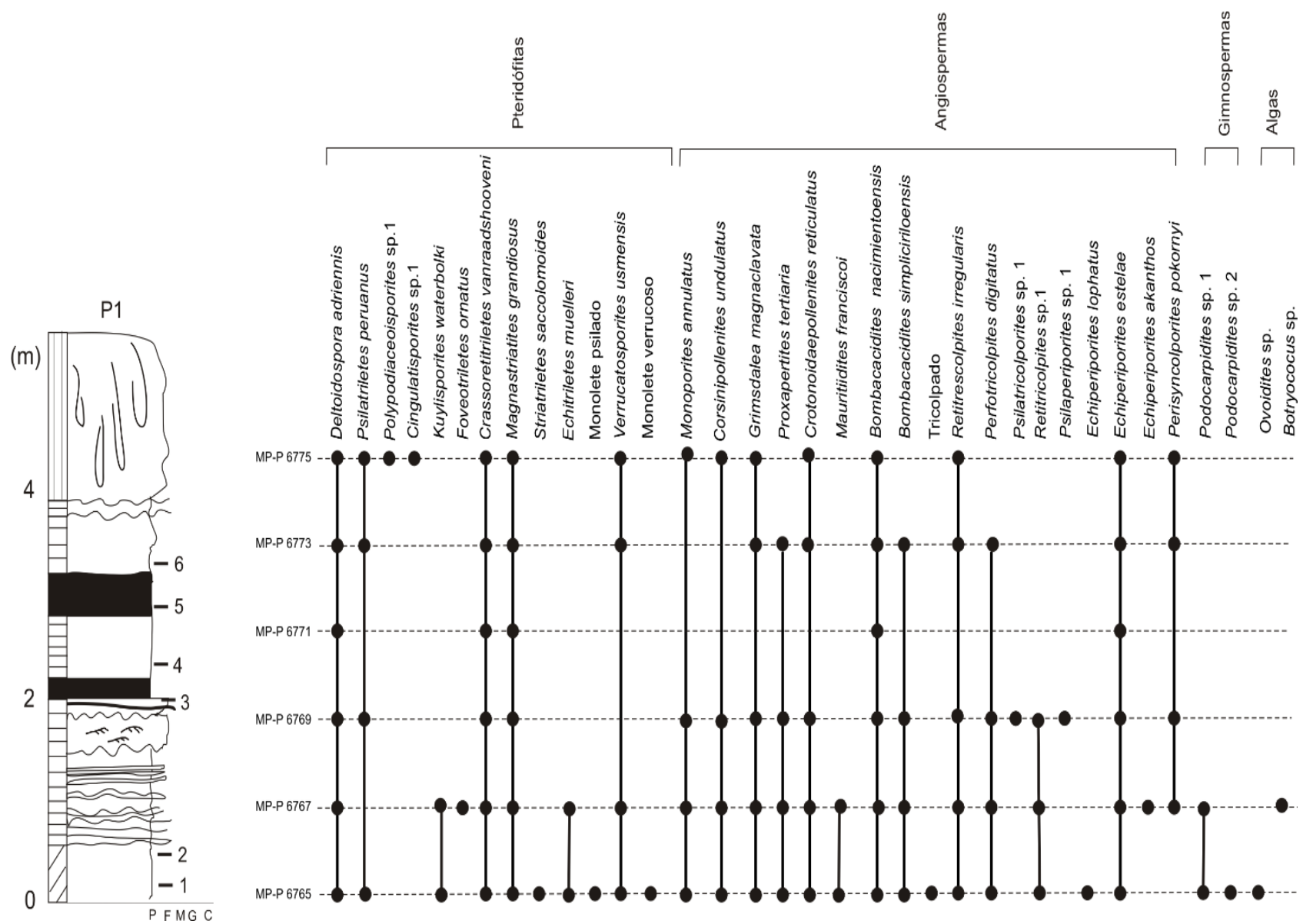

Figura 3. Distribuição estratigráfica dos táxons registrados no ponto $\mathrm{P} 1$, na estrada BR-307, entre Atalaia do Norte e Benjamin Constant, região do Alto Solimões, Amazonas. Pontos pretos: correspondem a níveis de ocorrência; MP-P: referente à codificação de lâminas da Palinoteca do Laboratório de Palinologia Marleni Marques Toigo; a numeração de 1 a 6: níveis amostrados. 


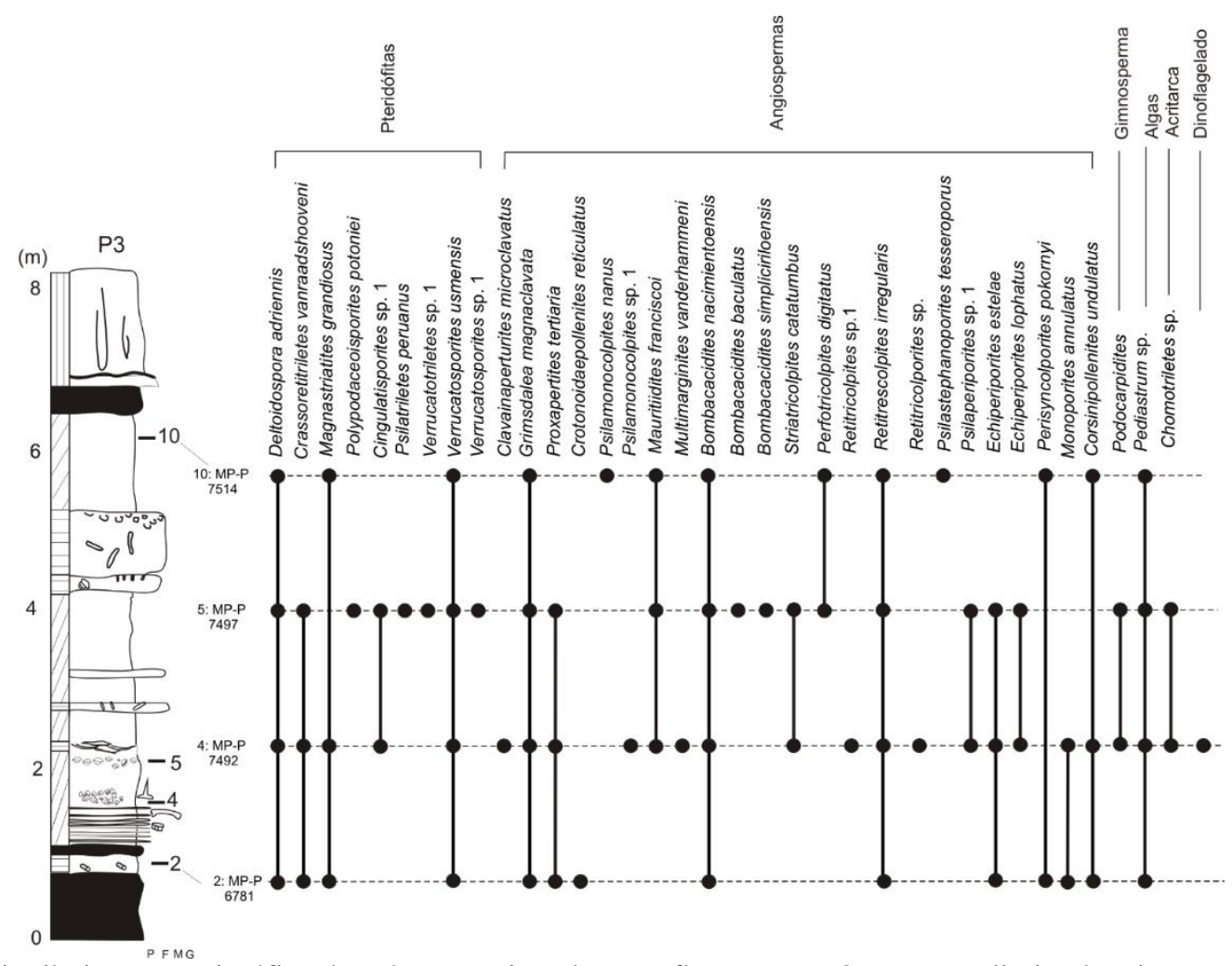

Figura 4. Distribuição estratigráfica dos táxons registrados no afloramento P3, margem direita do Rio Javari, Atalaia do Norte, região do Alto Solimões, Amazonas. Pontos pretos correspondem a níveis de ocorrência; MP-P: referente à codificação de lâminas da Palinoteca do Laboratório de Palinologia Marleni Marques Toigo; a numeração de 2 a 10 : níveis amostrados.

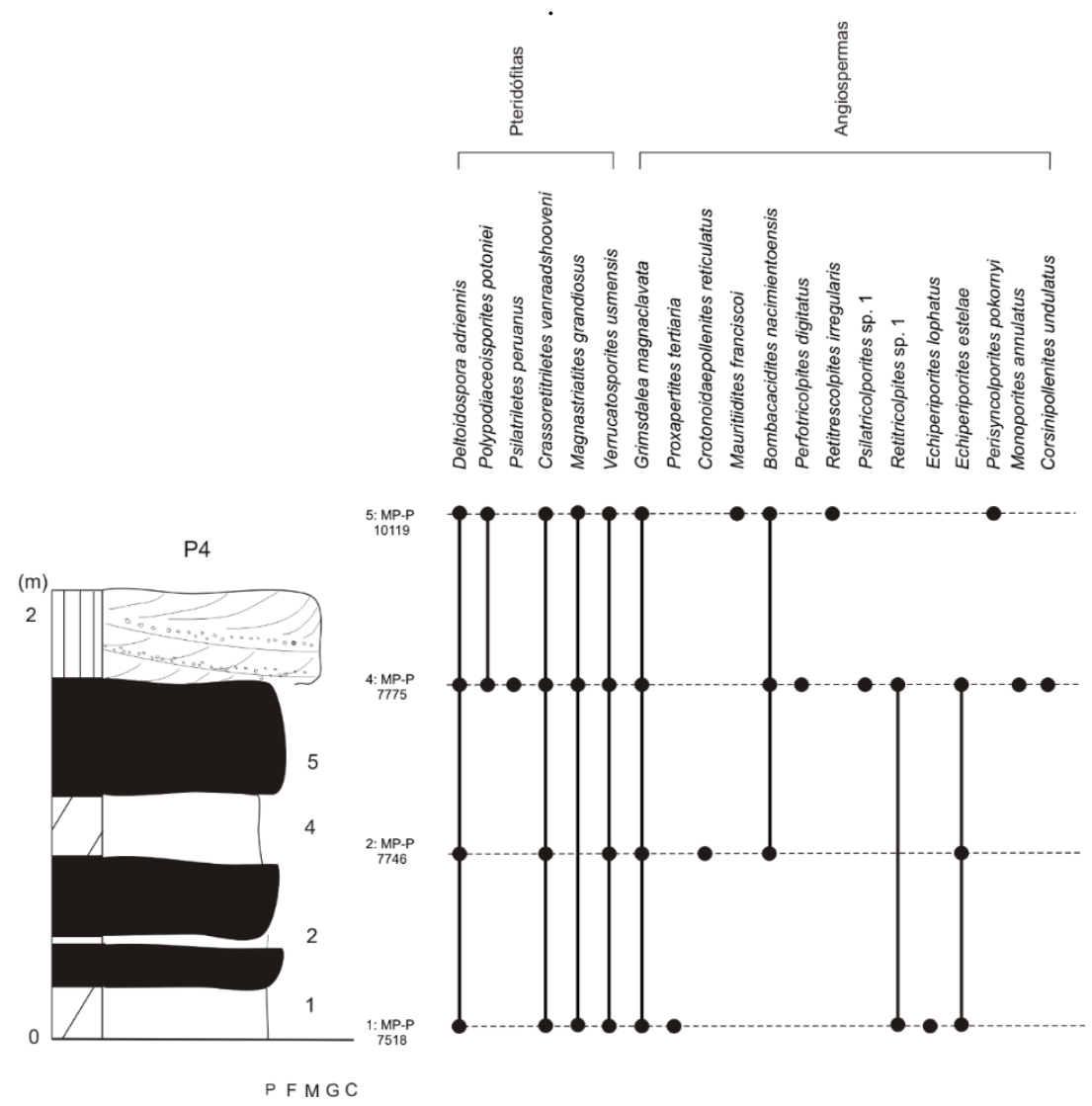

Figura 5. Distribuição estratigráfica dos táxons registrados no afloramento P4, margem direita do Rio Solimões,

Tabatinga, região do Alto Solimões, Amazonas. Pontos pretos correspondem a níveis de ocorrência; MP-P: referente à codificação de lâminas da Palinoteca do Laboratório de Palinologia Marleni Marques Toigo; a numeração de 1 a 5 : níveis amostrados. 


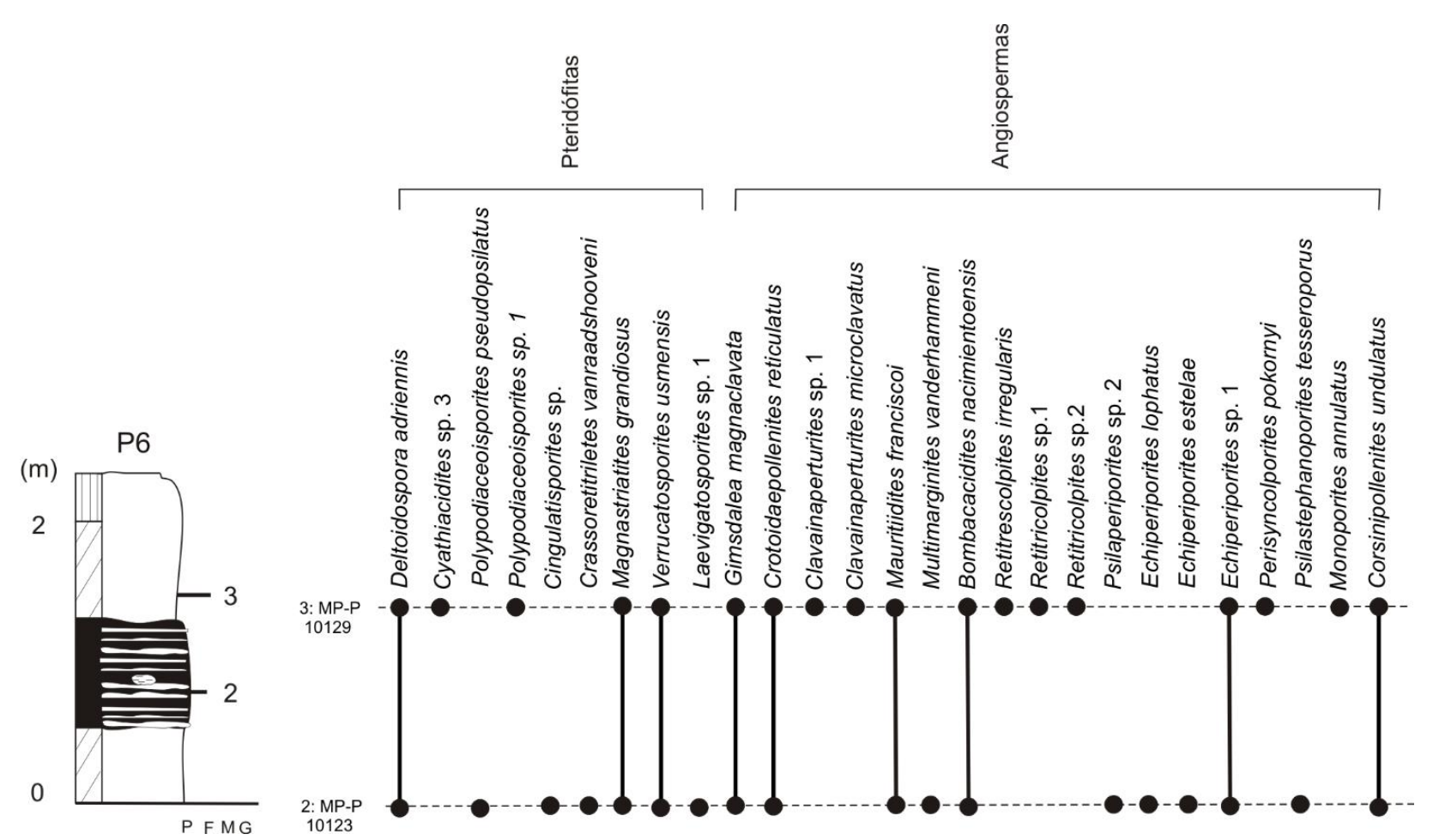

Figura 6. Distribuição estratigráfica dos táxons registrados no afloramento P6, margem direita do Rio Solimões,

Tabatinga, região do Alto Solimões, Amazonas. Pontos pretos correspondem a níveis de ocorrência; MP-P: referente à codificação de lâminas da Palinoteca do Laboratório de Palinologia Marleni Marques Toigo; a numeração de 2 a 3: níveis amostrados.

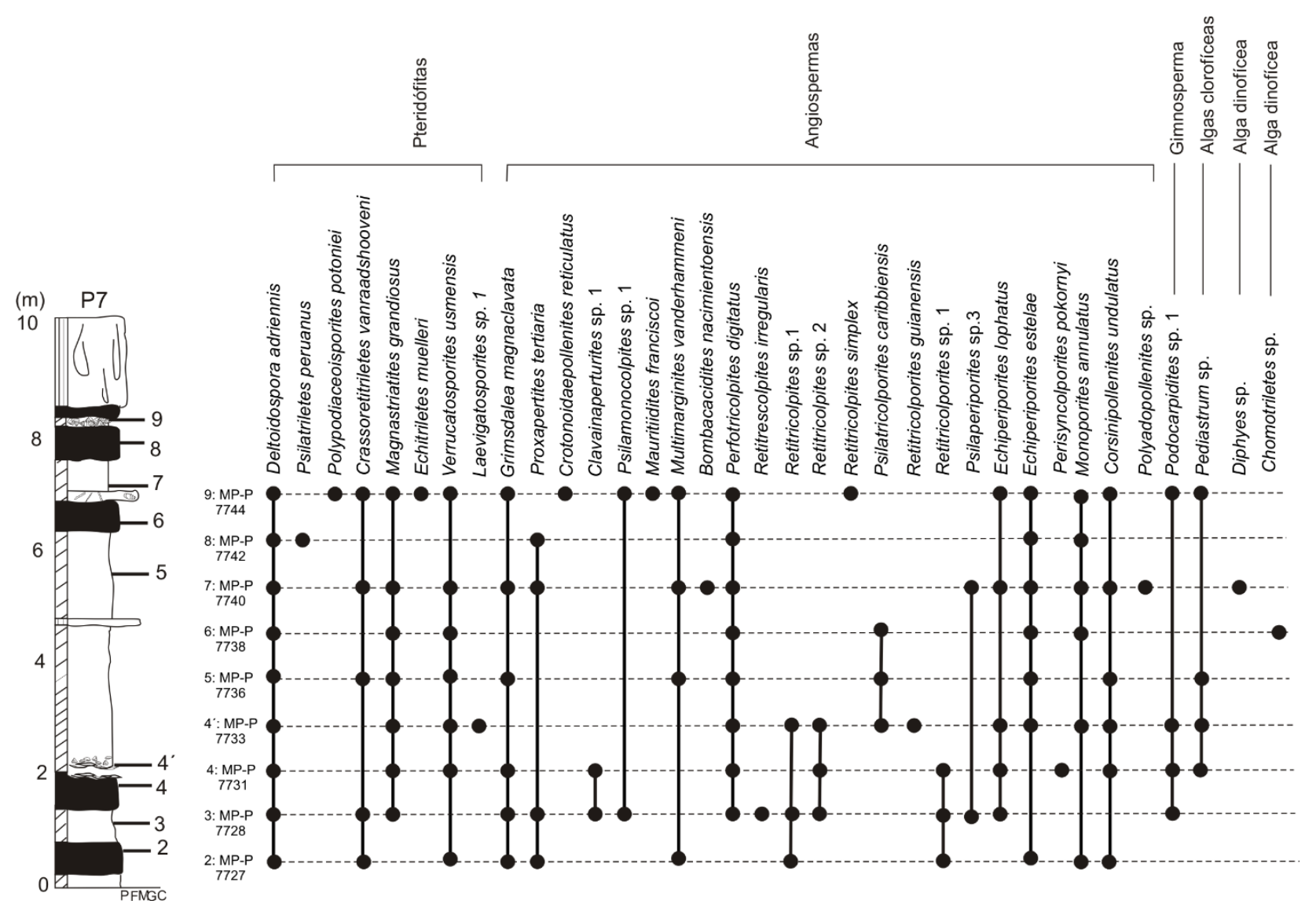

Figura 7. Distribuição estratigráfica dos táxons registrados no afloramento P7, margem direita do Rio Solimões,

Tabatinga, região do Alto Solimões, Amazonas. Pontos pretos correspondem a níveis de ocorrência; MP-P: referente à codificação de lâminas da Palinoteca do Laboratório de Palinologia Marleni Marques Toigo; a numeração de 2 a 9: níveis amostrados. 


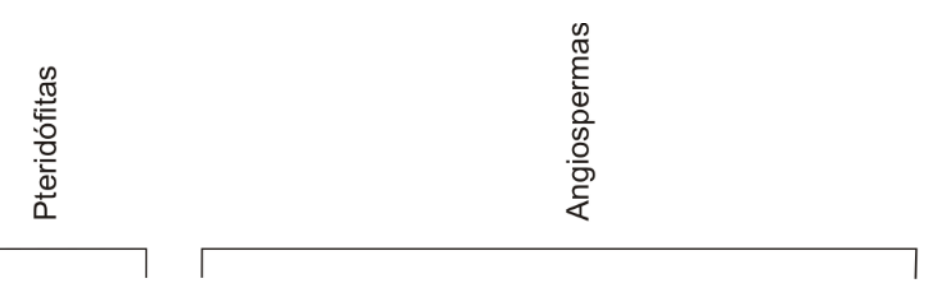

$\frac{\sqrt[n]{0}}{\frac{\pi}{0}}$

P8

(m)

6

4

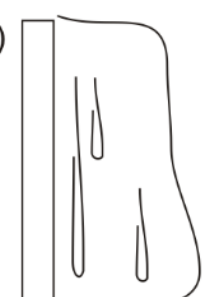

2

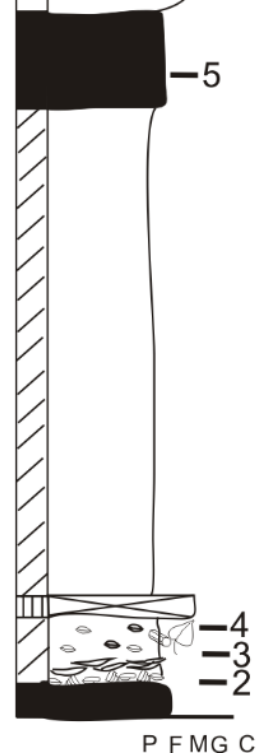

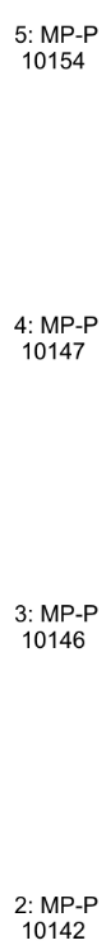

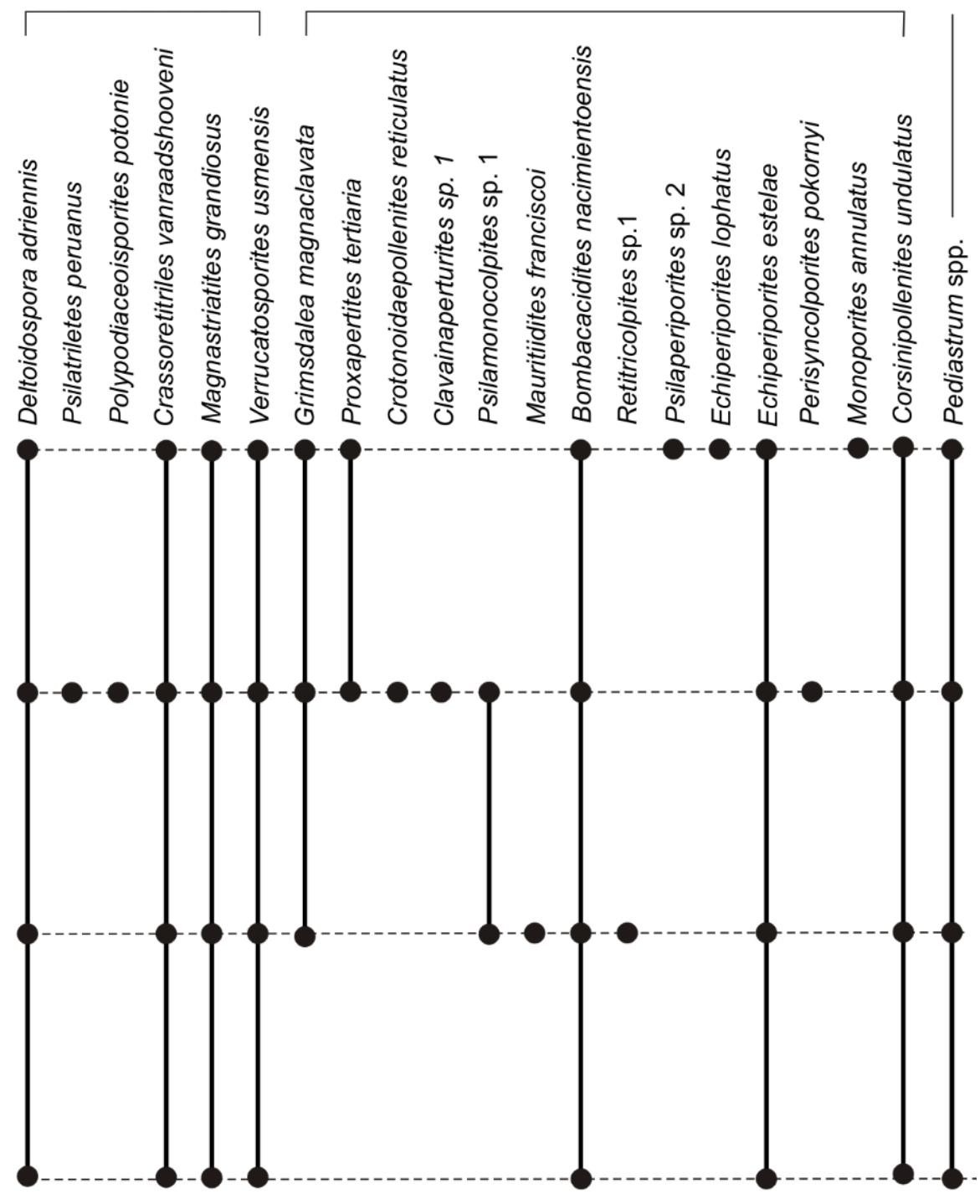

Figura 8. Distribuição estratigráfica dos táxons registrados no afloramento P8, margem direita do Rio Solimões,

Tabatinga, região do Alto Solimões, Amazonas. Pontos pretos correspondem a níveis de ocorrência; MP-P: referente à codificação de lâminas da Palinoteca do Laboratório de Palinologia Marleni Marques Toigo; a numeração de 2 a 5: níveis amostrados.

Por outro lado, outros são considerados marcadores bioestratigráficos, tais como Jandufouria Psilastephanoporites Crassoretitriletes Bombacacidites seamrogiformis, tesseroporus, vanraadshoovenii, nacimientoensis,
Psilamonocolpites nanus, Psilatricolporites caribbiensis e Grimsdalea magnaclavata, além da espécie de dinocisto Diphyes sp. Na foto 1 são ilustrados palinomorfos selecionados dentre aqueles com valor bioestratigráfico. 


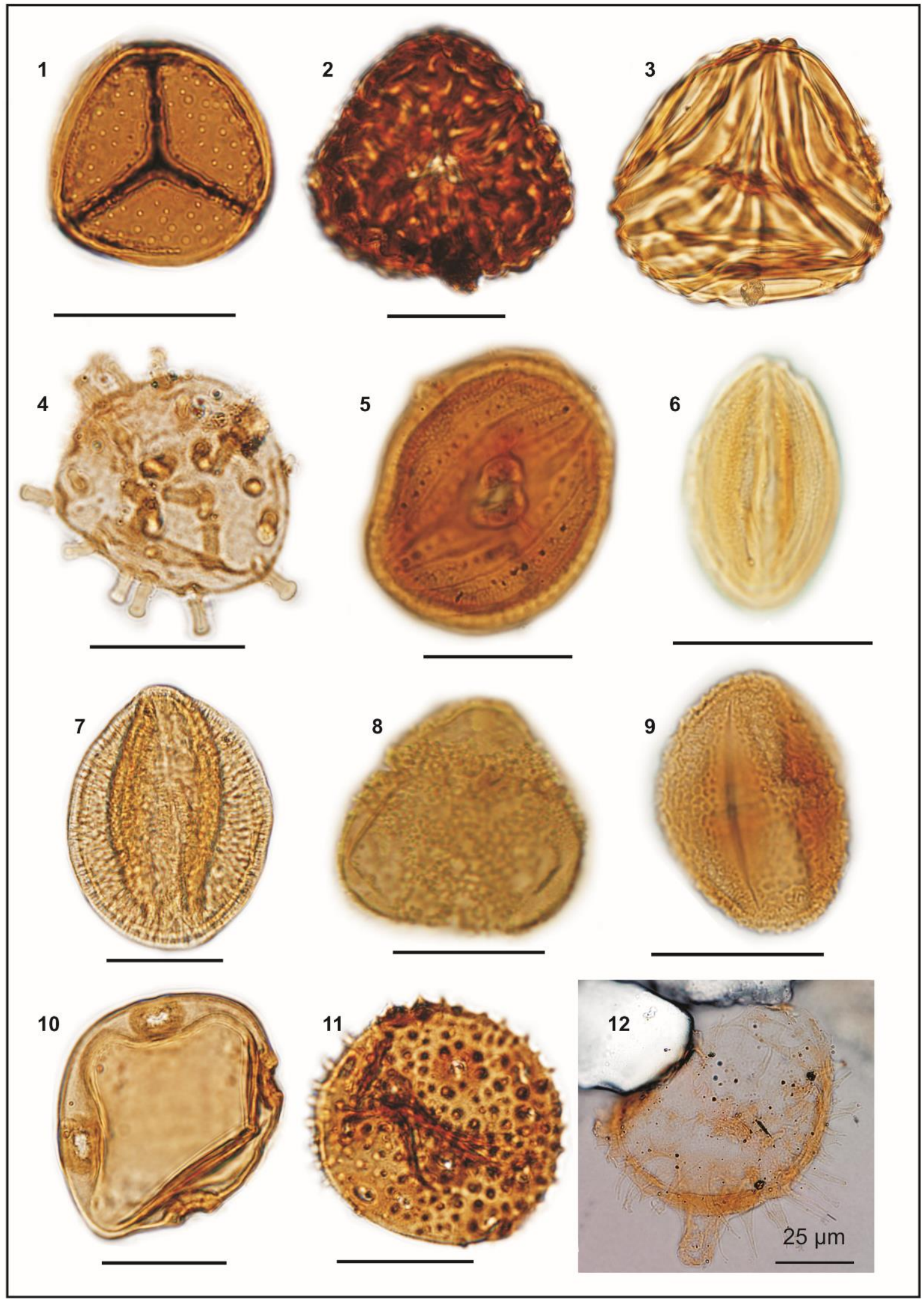

Foto 1. Fotomicrografias de palinomorfos selecionados empregados como marcadores bioestratigráficos. 1)

Foveotriletes ornatus; 2) Crassoretitriletes vanraadshooveni; 3) Magnastriatites grandiosus;4) Grimsdalea magnaclavata; 5) Multimarginites vanderhammeni; 6) Striaticolpites catatumbus; 7) Perfotricolpites digitatus, 8) Bombacacidites baculatus; 9) Retitricoporites guianensis; 10) Psilastephanoporites tesseroporus; 11) Echiperiporites cf. estelae; 12) Diphyes latiusculum. 


\section{DISCUSSÃO DOS RESULTADOS}

\section{Idade e correlação da palinoflora}

Considerando os levantamentos palinológicos do norte da América do Sul (Germeraad et al., 1968; Regali, 1971; Regali et al., 1974a,b; Lorente, 1986; Muller et al., 1987; Leite, 2006; Silva, 2008; Silva-Caminha et al., 2010), observa-se que grande parte das espécies registradas neste trabalho apresenta distribuição estratigráfica variável entre o Mioceno e o Plioceno. Foram reportados na região do Alto Solimões os esporomorfos Crassoretitriletes vanraadshooveni, Magnastriatites grandiosus, Deltoidospora adriennis, Foveotriletes ornatos, Cyathidites sp. 1, Cyathidites. sp. 2, Cyathidites. sp. 3, Kuylisporites waterbolkii, Psilatriletes peruanus, Echitriletes muelleri, Laevigatosporites sp. 2, Verrucatosporites usmensis, Clavainaperturites sp.,
Crotoidaepollenites reticulatus, Grimsdalea magnaclavata, Mauritiidites franciscoi, Multimarginites vanderhammeni, Retitrescolpites magnus, Striatricolpites catatumbus, Perfotricolpites digitatus, Retitricolpites sp., $\quad$ Bombacacidites nacimientoensis, $\quad B . \quad$ simpliciriloensis, $\quad B$. baculatus, Retitricolporites guianensis, Retitricolporites. sp. 1, Retitricolporites sp. 2, Psilatricolporites caribbiensis, Psilastephanoporites tesseroporus, Jandufouria seamrogiformis, Corsinipollenites undulatus, Echiperiporites akanthos e E. cf. estelae, que são apresentados em Silveira \& Souza (2015, 2016). São ressaltados aqui somente aqueles de amplitude com significado bioestratigráfico, conforme sintetizado na figura 9.

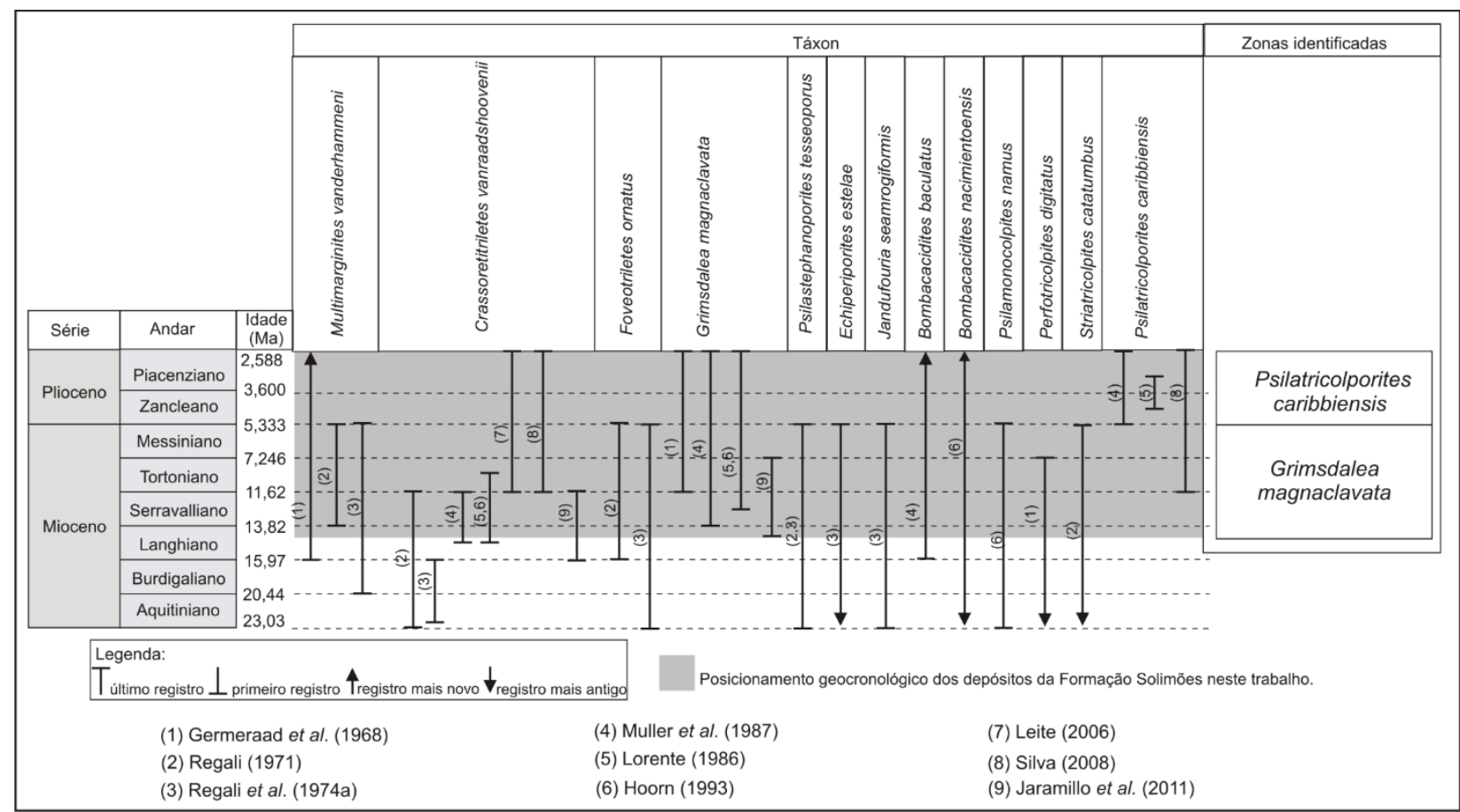

Figura 9. Amplitude estratigráfica de espécies guias identificadas nas amostras deste trabalho conforme literatura.

Algumas das angiospermas listadas têm correspondência com outras identificadas na porção oeste da Amazônia, tanto em amostras de superfície (Hoorn, 1994; Silveira \& Souza, 2015), quanto de subsuperfície (Hoorn, 1993; Silva-Caminha et al., 2010). Os trabalhos de Hoorn $(1993,1994)$ reportam uma associação entre Grimsdalea magnaclavata e Crassoretitriletes vanraadshooveni, a partir da Zona Grimsdalea (Mioceno médio a superior), que já havia sido verificado por Lorente (1986).
Grimsdalea

magnaclavata

e Crassoretitriletes vanraadshooveni ocorrem em todas as três biozonas citadas por Silva-Caminha et al. (2010), em que os depósitos se relacionam ao intervalo Mioceno superior - Plioceno. O presente trabalho apresenta em comum com Silva-Caminha et al. (2010) a presença de Crotoidaepollenites reticulatus e Perfotricolpites digitatus, entre outros que serão discutidos a seguir, além de Magnastriates grandiosus, este último apresentado em Silveira 
(2015). Silva-Caminha et al. (2010) assinalam ainda a presença de Cichoreacidites longispinosus (=Fenestrites longispinosus), que ocorre entre as profundidades de $43 \mathrm{~m}$ a aproximadamente $350 \mathrm{~m}$ do poço 1AS-27-AM, bem como abaixo de $90 \mathrm{~m}$ do poço $1 \mathrm{AS}-19-\mathrm{AM}$.

Cichoreacidites longispinosus $(=$ Fenestrites longispinosus) não é encontrada em amostras de superfície por Hoorn (1994), embora a autora reconheça a presença dessa família (Asteraceae), uma vez que identificou Echitricolporites spinosus, sempre em baixos números.

Silva (2008) chamou a atenção ao fato de Clavainaperturites microclavatus ser interpretado por Hoorn (1994) como tendo primeira ocorrência no Mioceno médio, mas em suas seções de Santa Sofía, Mocagua e Los Chorros (Colômbia) o táxon ocorre em associação com Stephanocolpites evansii. De acordo com Lorente (1986), S. evansii é de idade pliocena, o que permitiu a Silva (2008) correlacionar suas associações com estas. Silveira (2015) também correlacionou os perfis estratigráficos estudados no Alto Solimões com os de Hoorn (1994), sem a presença de Psilatricolporites caribbiensis, posicionando os depósitos investigados no SerravalianoTortoniano. Silva (2008) nomeou Psilatricolporites caribbiensis como Horniella? caribbiensis, e mais tarde Silva-Caminha et al. (2010) o chamaram de Ladakhipollenites ? caribbiensis. Sua ocorrência está abaixo de $90 \mathrm{~m}$ no poço 1AS-19-AM, e entre aproximadamente $43 \mathrm{~m}$ a $220 \mathrm{~m}$ do poço $1 \mathrm{AS}-27-\mathrm{AM}$ (Silva, 2008; Silva-Caminha et al., 2010).

Com base na presença de Cichoreacidites longispinosus (Fenestrites longispinosus), um representante de Asteraceae, Silva-Caminha et al. (2010) relacionaram às últimas biozonas propostas por Lorente (1986), na fase final do Neógeno (Mioceno final-Plioceno), tendo ainda reportado raras ocorrências de Stephanocolpites evansii e H. ? caribbiensis/ L. ? caribbiensis, o que obrigou o uso de outros marcadores, muitas novas formas, para limitar seus intervalos temporais.

Tanto as associações apresentadas por Hoorn (1993, 1994) quanto por Silva-Caminha et al. (2010) mostram maior diversidade de grãos de pólen de angiospermas que os registrados aqui. Particularmente, o gênero Bombacacidites é representado por três espécies: $B$. nacimientoensis, $\quad$ B. baculatus e $B$. simpliciriloensis nos estratos superficiais da região do Alto Solimões (Silveira, 2015). Importante frisar que a espécie nomeada como B. ciriloensis, tanto em Silveira (2005, 2015), quanto em Nogueira et al. (2013), é referente a B. nacimientoensis (Silveira \& Souza, 2015).

Hoorn (1993) identificou B. baculatus, contudo em Hoorn (1994) esse táxon não ocorre, assim como não há documentação de $B$. simpliciriloensis e B. nacimientoensis. SilvaCaminha et al. (2010) também registraram variação no gênero, onde Bombacacidites baculatus e $B$. nacimientoensis ocorrem entre 105 e $264 \mathrm{~m}$ de profundidade do poço 1-AS-27AM, e 218 m de profundidade, no poço 1AS-19AM. Em todos os níveis estratigráficos apresentados por esses autores, sua ocorrência é de baixa representação, o que os diferencia do trabalho ora apresentado. Em particular ao que trata da ocorrência de B. nacimientoensis, SilvaCaminha et al. (2010) contaram oito espécimes para os poços analisados, contra 1236 espécimes aqui contados. Os autores documentam ainda a presença de $B$. simpliciriloensis em vários níveis estratigráficos dos poços investigados, variando de aproximados 49 a $354 \mathrm{~m}$, onde atingiram até 17 espécimes de sua contagem original.

No presente trabalho, Jandufouria seamrogiformis é rara, e não foi reportado por Hoorn $(1993,1994)$. Entretanto, Silva-Caminha et al. (2010) encontraram um único representante deste táxon a aproximadamente $264 \mathrm{~m}$ de profundidade, no poço 1-AS-27-AM, referente à Zona $\mathrm{B}$ daqueles autores.

A presença de Psilatricolporites caribbiensis, apresentada neste trabalho, mais a associação de forma comuns à Hoorn (1994) e Silva-Caminha et al. (2010) constitui dado significativo. Em Silveira (2105), Psilatricolporites caribbiensis ocorre em um único perfil estratigráfico, situado na região de Tabatinga, onde houve o registro de um único dinoflagelado.

Isso conduz às seguintes possibilidades: 1) biocron de Psilatricolporites caribbiensis e Stephanocolpites evansii deve ser ampliado, abarcando o intervalo Mioceno final, como mostrado em quadro de comparação entre biozonas de Silva-Caminha et al. (2010), o que justificaria a associação e a influência marinha no Mioceno final, propostas por Hoorn (1993, 1994); contudo, compromete a aplicação dessa 
parte do zoneamento de Lorente (1986); 2) as idades dos depósitos da Formação Solimões na região do Alto Solimões variam de Mioceno médio a final (maioria dos depósitos) ao Plioceno (pelo menos um afloramento), confirmado pela presença de Psilatricolporites caribbiensis, importante forma guia do biozoneamento proposto por Lorente (1986), que nesse caso pode ser aplicado com segurança, ainda que não haja outros marcadores; essa interpretação corrobora as idades propostas por Leite (2006) e Silva-Caminha et al. (2010), remetendo à primeira documentação da influência marinha para o Plioceno, para esses depósitos.

De acordo com Dino et al. (2012), no Mioceno médio, a Amazônia Central esteve submetida à condições quentes e úmidas, com vegetação composta por floresta de palmeiras (Mauritia, Grimsdalea) e elementos de várzeas (Gramineae, Bombacacea). A presença destes táxons de angiospermas indica que também durante o Mioceno final e Plioceno, essas condições ambientais eram comuns para a porção ocidental.

Esta associação não apresenta correspondência com as reconhecidas na Amazônia Central descritas por Dino et al. (2006, 2012), Soares et al. (2015) e Guimarães et al. (2015), os quais registraram a espécie Grimsdalea magnaclavata. Dino et al. (2006, 2012), com base na frequência de Grimsdalea, associado a Mauritidiites franciscoi, Perisyncolporites pokornyi, Striatopollis (Striatricolpites) catatumbus, Bombacacidites baumfalki, Retitricolpites (Tricolpites) simplex e Polypodiisporites (Verrucatosporites) usmensis, atribuíram idade mesomiocênica para a Formação Novo Remanso, apoiados no zoneamento apresentado por Jaramillo et al. (2011), os quais limitam a Biozona Grimsdalea ao Mioceno médio, ainda que Lorente (1986) e Hoorn (1993) posicionem essa associação entre Mioceno médio e superior.

Guimarães et al. (2015) questionaram a idade atribuída por Dino et al. (2012), já que Germeraad et al. (1968) relataram a última ocorrência de Grimsdalea no Plioceno, e se apoiam em Silva-Caminha et al. (2010), que apresentam esse gênero em muitos níveis estratigráficos de seus poços, como discutido anteriormente. Com base na associação de $G$. magnaclavata, Psilatricolporites crassoexinatus, Proteacidites triangulatus, Bombacacidites simpliciriloensis, Pteridaceoisporites gemmatus

Cingulatisporites laevigatus, Guimarães et al. (2015) defenderam idade entre o Mioceno final e o Plioceno para a Formação Novo Remanso. No entanto, Silva-Caminha et al. (2010) não reportaram a ocorrência de Psilatricolporites crassoexinatus em nenhum dos poços estudados, como defendem Guimarães et al. (2015). Hoorn (1993) e Jaramillo et al. (2011) registraram $P$. triangulatus em rochas mais antigas que Mioceno final-Plioceno, e $B$. simpliciriloensis ocorre em camadas consideradas como do Mioceno médio a final, como apresentado aqui. Em Guimarães et al. (2015), não é reportada qualquer espécie típica do Plioceno. Um dado muito interesante é a identificação de Elaterosporites klaszii nas associacões reportadas por Guimarães et al. (2015), o que sugere contribuição de rochas cretáceas na área de acumulação.

Soares et al. (2015) posicionaram os depósitos estudados na porção central da Amazônia no Mioceno médio, empregando o zoneamento de Jaramillo et al. (2011), com associações continentais, compreendendo Bombacacidites baumfalki, Crototricolpites annemariae e Psilastephanoporites tesseroporus. Segundo Soares et al. (2015), a associação palinológica apresentada por Guimarães et al. (2015) não fornece boa resolução bioestratigráfica, não inclui táxons andinos, ou mesmo marcadores estratigráficos do Plioceno. De acordo com Jaramillo et al. (2011), Psilastephanoporites tesseroporus tem seu primeiro registro na zona Crassoretitriletes vanraadshoovenii, que nesse zoneamento é mais jovem que a Zona Grimsdalea magnaclavata. No entanto, as formas homônimas aos zoneamentos não são reportadas pelos autores.

Os dados palinológicos da Formação Solimões da região de Coari divulgados por Silveira (2005, 2015), Silveira \& Nogueira (2007, 2008), Nogueira et al. (2013), Silveira \& Souza $(2015,2016)$ sugerem idades que variam de Mioceno final ao Plioceno. Para a Formação Içá, estabeleceram idade pleistocena.

Silveira (2005) baseou-se no reconhecimento de Fenestrites spinosus, que ocorre a partir do Mioceno final, relatando a ocorrência de 
Alnipollenites verus para a Formação Içá, onde foi interpretado um contexto fluvio-lacustre para as formações Solimões e Içá. Além disso, a autora identificou contribuição de depósitos paleozoicos e mesozoicos na sedimentação da Formação Solimões, a partir do recohecimento de palinomorfos retrabalhados daquelas idades. Silveira \& Nogueira $(2007,2008)$ apoiados em levantamentos estratigráficos divulgados por Vega (2006) modificaram a interpretação paleoambiental da Formação Solimões para um contexto flúvio-deltáico, tendo reconhecido as facies de prodelta e frente deltaica como favoráveis a preservação de palinomorfos. Em Silveira \& Nogueira (2008) foi registrada a presença de Fenestrites spinosus, que posiciona os depósitos da Formação Solimões entre o Mioceno final e o Plioceno.

Nogueira et al. (2013) renomearam táxons apresentados por Silveira (2005). Silveira \& Nogueira $(2007,2008)$, em particular quanto ao reconhecimento de guias, como Fenestrites longispinosus e Stephanocolpites evansii, detalharam a estratigrafía da área, enfatizando o papel do Arco de Purus na geração das acumulações na região de Coari. Ainda em Nogueira et al. (2013), foram constatadas concentrações relativamente elevadas de $F$. longispinosus e Fenestrites spinosus, em associação com Echitricolporites spinosus e Bombacacidites. ciriloensis. Essa característica não é constatada por Silveira (2015), Silveira \& Souza (2015) e, apesar de B. ciriloensis (aqui chamada de Bombacacidites. nacimientoensis) se apresentar em abundância em alguns níveis estratigráficos no Alto Solimões, é espécie rara na região de Coari, nas formações Solimões e Içá.

No zoneamento de Germeraad et al. (1968), estabelecido para estratos mesozoicos e cenozoicos da Venezuela, Multimarginites vanderhammeni distribui-se entre o Mioceno médio e o Plioceno. No oeste da Venezuela, Lorente (1986) registrou a espécie na Zona Crassoretitriletes (Mioceno médio), enquanto para a margem costeira brasileira, ocorre ao longo das zonas Crassoretitriletes vanraadshooveni e Grimsdalea magnaclavata, aproximadamente entre a metade do Mioceno inferior e o Mioceno superior (Regali et al., 1974a, 1974b). Esta espécie ocorre em alguns níveis estratigráficos dos afloramentos P3, P6 e P7.

Foveotriletes ornatos ocorre somente no afloramento $\mathrm{P} 1$, sendo espécie de distribuição estratigráfica restrita na Zona Pachydermites diederixi estabelecida por Regali (1971) na Foz do Amazonas, com idade entre o Mioceno médio e final. Jandufouria seamrogiformis e Psilastephanoporites tesseroporus também são registrados nesta zona, de forma indiferenciada no Mioceno.

Com base no levantamento bioestratigráfico desenvolvido na Colômbia e áreas adjacentes, empregando palinologia e foraminíferos, Jaramillo et al. (2011) registraram a ocorrência de Grimsdalea magnaclavata e Crassoretitriletes vanraadshooveni, interpretando idades distintas com relação aos dados preexistentes. De acordo com aqueles autores, a Zona Grimsdalea magnaclavata (T14) tem a base delimitada pelo aparecimento da espécie epônima, com topo marcado pelo aparecimento de Crassoretitrileres vanraadshoveni. A idade desta zona foi atribuída ao Mioceno inicial ao médio. Já a Zona Crassoretitriletes vanraadshooveni (T-15) tem a base marcada pelo primeiro registro da forma homônima, e topo a partir do primeiro registro de Fenestrites spinosus, com idade interpretada no Mesomioceno.

Considerando os zoneamentos de Lorente (1986) e Hoorn (1993), a presença da espécie guia Grimsdalea magnaclavata e Psilatricolporites caribbiensis permite comparação com as zonas Grimsdalea e Psilatricolporites caribbiensis, a qual está associada com Crassoretitriletes vanraadshooveni, Foveotriletes ornatus, Multimarginites vanderhammeni, Foveotriletes ornatus, Bombacacidites nacimientoensis, Jandufouria seamrogiformis e Psilastephanoporites tesseroporus, indicando idades entre o Neomioceno e Plioceno.

O gênero Diphyes foi documentado por Matsuoka (1974) na Formação Toyoda (Grupo Fujiwara), porção central do Japão, representado por D. latiusculum, com idade entre o Eomioceno e o Mesomioceno, e D. colligerum, encontrado em depósitos de idade paleocênica a neoeocênica. Um único dinocisto atribuído ao gênero foi reportado em Silveira (2015), que na ocasião sugeriu idade serravaliana-tortoniana. 
No entanto, a presença de Psilatricolporites caribbiensis com esta alga dinofícea, marca idade Pliocena. A atribuição de influência marinha efetiva a partir de uma única espécie é insegura, mas sua ocorrência não deve ser ignorada.

Boonstra et al. (2015), com base na releitura de material coletado por outros pesquisadores entre os anos 1988 e 2003, apresentaram farta documentação da influência marinha (dinocistos, palinoforaminíferos e foraminíferos) em áreas da Colômbia e Peru, e os relacionam ao Mioceno. Para esses autores o mar poderia ter avançado até $2000 \mathrm{~km}$ para o interior do continente, a partir do mar do Caribe, mas no Plio-Pleistoceno, o rebaixamento do nível do mar e mudanças nos regimes tectônicos finalizaram essas incursões.

A maioria dos depósitos investigados neste trabalho corresponde à Zona Grimsdalea, e são correlatos, em subsuperfície, aos depósitos que variam de $89 \mathrm{~m}$ a 23,5 $\mathrm{m}$ de profundidade do poço 1AS-51-AM de Hoorn (1993). Esta autora correlaciona o poço às seções da Colômbia, em superfície (Hoorn, 1994). Neste trabalho a autora fez também correlação da zona com depósitos ocorrentes em Benjamin Constant e Atalaia do Norte, no estado do Amazonas.

Os resultados apresentados aqui também encontram correlação com os dados palinológicos de subsuperfície do poço 1AS-33AM de Leite (2006). Dos 299,05 a 238,33 m de profundidade, corresponde à Zona Asteraceae, com idade Mioceno final, enquanto entre 238,33 a 185,0 $\mathrm{m}$ de profundidade, é relativo à Zona Psilatricolporites caribbiensis, de idade pliocênica.

Ainda que os depósitos da Formação Novo Remanso, na Amazônia Central estudados por Dino et al. (2012) tenham apresentado a ocorrência de Grimsdalea magnaclavata, a associação de esporomorfos é muito distinta do conjunto palinológico levantado para a região do Alto Solimões; o conjunto reconhecido por aqueles autores denota idade mais jovem que os estudados neste trabalho.

\section{CONCLUSÕES}

Os palinomorfos registrados nos depósitos superficiais da região adjacentes de Atalaia do Norte e Tabatinga, Amazônia Ocidental (Amazonas, Brasil), mostraram eficiência em termos bioestratigráficos, com presença de espécies guias significativas. Determinadas espécies, tais como Grimsdalea magnaclavata, Crassoretitriletes vanraadshooveni,

Foveotriletes ornatus, Bombacacidites ciriloensis, Multimarginites vanderhammeni, Foveotriletes ornatus, Jandufouria seamrogiformis, Psilastephanoporites tesseroporus e Psilatricolporites caribbiensis permitem o reconhecimento das zonas Grimsdalea e Psilatricolporites caribbiensis, previamente reconhecida na Formação Solimões e na Amazônia venezuelana, atribuída aos intervalos Mioceno médio/superior ao Plioceno. Depósitos dessa idade são também registrados às margens de rios da Colômbia e Peru.

A presença de Diphyes sp. (dinoflagelado) no material estudado sugere influência de águas marinhas na área de Tabatinga, ainda que seu registro seja relativo a apenas um nível estratigráfico, e sua associação com a forma guia Psilatricolporites caribbiensis indica idade Pliocena para essa fase. Estes resultados, no entanto, não contradizem o levantamento anterior de Hoorn (1993) ou Boonstra et al. (2015), que registram incursões marinhas no Mioceno médio a superior, mas assinala sua primeira evidência em depósitos do Plioceno para amostras de superfície.

\section{AGRADECIMENTOS}

Os autores agradecem a FAPEAM e ao CNPq pelo financiamento das atividades de campo e pela concessão de bolsa de doutorado e de produtividade em pesquisa (Processos CNPq 142102/2010-5 e 308844/2010-6). Este trabalho é parte da Tese de Doutoramento da primeira autora, desenvolvida no Programa de Pós-Graduação em Geociências do Instituto de Geociências da UFRGS.

\section{REFERÊNCIAS BIBLIOGRÁFICAS}


1. ARAI, M.; NOGUEIRA, A.C.R.; SILVEIRA, R. R.; HORBE, A.M.C. Considerações Cronoestratigráficas e Paleoambientais da Formação Solimões com base em palinomorfos, região de Coari, Estado do Amazonas. In: SIMPÓSIO DE GEOLOGIA DA AMAZÔNIA, 8, 2003, Manaus. Resumos expandidos...SGA, 2003, CDRom..

2. BOONSTRA, M.; RAMOS, M.I.F.; LAMMERTSMA, E.I.; ANTOINE, P.O; HOORN, C. Marine connections of Amazonia: Evidence from foraminífera and dinoflagellate cysts (early to middle Miocene, Colombia/Peru). Palaeogeography, Palaeoclimatology, Palaeoecology, v. 417, p. 176-194, 2015.

3. BRASIL. Folha SB. 19 Juruá - Levantamento de Recursos Naturais: Geologia, Geomorfologia, Pedologia, Vegetação e Uso Potencial da Terra. 1978.

4. CAPUTO, M.V. Stratigraphy, Tectonics, Paleoclimatology and Paleogeography of Nortern Basin of Brazil. Universidade da California, 1984. Tese (Doutorado em Geociências), 583 p.

5. CAPUTO, M. V.; RODRIGUES, R. \& VASCONCELOS, D. N.: Litoestratigrafia da Bacia do Amazonas. Relatório Técnico Interno da Petrobrás, p.35-46, 1971.

6. CAPUTO, M.V. \& SILVA, O.B. Sedimentação e tectônica da Bacia do Solimões. In: RAJA GABAGLIA, G.P. \& MILANI, E.J. (Coordenadores), Origem e Evolução das Bacias Sedimentares. Rio de Janeiro: PETROBRÁS, p. 169-193, 1991. 7. CRUZ, N.M.C. Palinologia do Linhito do Solimões no Estado do Amazonas. In: II SIMPÓSIO DE GEOLOGIA DA AMAZÔNIA, 2, 1984, Manaus. Resumos Expandidos...1984, p. 473-480.

8. CUNHA, P.R.C.; MELO, J.H.G.; SILVA, O.B. Bacia do Amazonas. Boletim de Geociências da Petrobrás, v.15, n.2, p. 227-251, 2007.

9. DAEMON, R.F. \& CONTREIRAS, C.J.A. Zoneamento palinológico da bacia do Amazonas. In: XXV CONGRESSO BRASILEIRO DE GEOLOGIA, 3, 1971, p. 79-91.

10. DINO, R.; SILVA, O.B.; ABRAHÃO, D. Caracterização palinológica e estratigráfica de estratos cretáceos da Formação Alter do Chão, Bacia do Amazonas. In: 5o. Simpósio sobre o Cretáceo do Brasil. Serra Negra, Boletim..., p.557-565, 1999. 11. DINO, R.; SOARES, E.A.A.; RICCOMINI, C.; ANTONIOLI, L.; NOGUEIRA, A.C.R. Caracterização Palinoestratigráfica de depósitos Miocênicos na Bacia do Amazonas, região de Manacapuru, AM. In: 7 Simpoósio do Cretáceo do Brasil e 1o Simpósio do Terciário do Brasil, Serra Negra. IGCE/UNESP, p43, 2006.

12. DINO, R.; SOARES, E.A.A.; ANTONIOLI, L.; RICCOMINI, C. \& NOGUEIRA, A.C.R. Palynostratigraph and sedimentar facies of Middle Miocene fluvial deposits of the Amazonas Basin, Brazil. Journal of South American Earth Sciences, v. 34, p. 61-80, 2012.

13. EIRAS, J.F.; BECKER, C.R.; SOUZA, E.M.; GONZAGA, F.G.; da SILVA, J.G.F.; DANIEL, L.M.F.; MATSUDA, N.S. \& FEIJÓ, F.J. Bacia do Solimões. Boletim de Geociências da Petrobrás, v. 8, n. 1, p. 17-45, 1994.

14. GERMERAAD, J.H.; HOPPING, C.A.; MULLER, J. Palynology of tertiary sediments from the tropical areas. Review Paleobotany and Palynology, v. 6, p. 89-348, 1968.

15. GUIMARÃES, J.T.F.; NOGUEIRA, A.C.R.; DA SILVA JUNIOR, J.B.C.; SOARES, J.L. \& SILVEIRA, R. Fossil Fungi from Miocene Sedimentary Rocks of the Central and Coastal Amazon Region, North Brazil. Journal of Paleontology, v. 87, n. 3, p. 484-492, 2013.

16. GUIMARÃES, J.T.F.; NOGUEIRA, A.C.R.; DA SILVA JUNIOR, J.B.C.; SOARES, J.L.; ALVES, R.; KERN, A.K. Palynology of the Middle Miocene-Pliocene Novo Remanso Formation, Central Amazonia, Brazil. Ameghiniana, v. 52, n. 1, p. 107-134, 2015.
17. HOORN, C. Marine incursions and the influence of Andean tectonics on the Miocene deposital history of northwestern Amazonia: results of a palynostratigraphic study. Palaogeography, Palaeoclimatology, Palaeoecology, v. 105, p. 277-309, 1993.

18. HOORN, C. Fluvial palaeoenvironments in the intracratonic Amazonas Basin (Early Miocene - early Middle Miocene, Colombia). Palaeogeography, Palaeoclimatology, Palaeoecology, v. 109, p. 1-54, 1994

19. JARAMILLO, C. A.; RUEDA, M., \& TORRES, V. A palynological zonation for the Cenozoic of the Llanos and Llanos Foothills of Colombia. Palynology, v.35, p.46-84, 2011.

20. LATRUBESSE, E.M.; COZZUOL, M.; SILVACAMINHA, S.A.F.; RIGSBY, C.A.; ABSY, M.L. \& JARAMILLO, C. Late Miocene paleogeography of the Amazon Basin and the Evolution of the Amazon River System. Earth Science Reviews, v.99, p. 99-124, 2010.

21. LATRUBESSE, E.M.; SILVA, S.A.F.; COZZUOL, M. \& ABSY, M.L. Late Miocene continental sedimentation in southwestern Amazonia and its regional significance: biotic and geological evidence. Review Journal South America Earth Science, v.23, p. 61-80, 2007.

22. LEANDRO, L. M. Análises palinoestratigráficas da Formação Solimões na porção noroeste do Alto Solimões, Amazonas, Brasil. São Leopoldo, 2012, 109p. Dissertação (Mestrado em Geologia), Instituto de Geociências, Universidade do Vale do Rio dos Sinos.

23. LEITE, F.P.R. Palinologia da Formação Solimões, Neógeno da Bacia do Solimões, Estado do Amazonas, Brasil: Implicações Paleoambientais e Bioestratigráficas. Brasília, 2006, 128p. Tese (Doutorado em Geociências) - Instituto de Geociências, Universidade de Brasília.

24. LORENTE, M.A. Palynology and palynofacies of upper Tertiary in Venezuela. Berlin, 1986, v.99, 222p. Tese (Doutorado Geociências) - Dissertationes Botanicae.

25. MATSUOKA, K. Some plant microfossils from the Miocene Fujiwara Group, Nara, Central

Japan. The Palaeontological Society of Japan, v.94, p. 319340, 1974.

26. MORAES-REGO, L.F. Notas sobre a Geologia do território de Acre e da Bacia do Javarí. Cezar \& Cavalcante (Coordenadores), DNPM, Manaus, 45p. 1930.

27. MULLER, J.; GIACOMO, E. \& VAN ERVE, A.W. A palynological zonation for the Cretaceous, Tertiary and Quaternary of Northern South America. American Association of Stratigraphic Palynologists Contribution Series, v.19, p.7$76,1987$.

28. NOGUEIRA, A.C.R.; SILVEIRA, R.R. \& GUIMARÃES, J.T.F. Neogene-Quaternary sedimentar and paleovegetation history of eartern Solimões Basin, central Amazon region. Jornal of South American Earth Sciences, v. 46, p. 89-99, 2013.

29. NUTTAL, C.P. A review of the Tertiary non marine molluscan faunas of the Pebasian and other inland basin of northwestern South America. Bulletin of the British Museum of Natural History Geology, v. 45, p.165-371, 1990.

30. PURPER, I. Cenozoic Ostracodes of the Upper Amazon Basin, Brazil. Pesquisas, 12: 209-281, 1979.

31. PURPER, I. \& ORNELLAS, L.P. New Ostracodes of the Endemic Fauna of the Pebas formation, Upper Amazon Basin, Brazil. Pesquisas, v.18, n.1, p. 25-30, 1991.

32. RAMOS, M.I.F. Ostracods from the Neogene Solimões Formation (Amazonas, Brazil). Journal of South America Earth Science, v. 21, p. 87-95, 2006.

33. REGALI, M.S.P. Palinologia dos Sedimentos Cenozóicos da Foz do Rio Amazonas. São Paulo, 1971, 118p. Tese (Doutorado em Geociências) - Instituto de Geociências, Universidade de São Paulo. 
34. REGALI, M.S.P.; UESUGUEI,N.; \& SANTOS, A.S. Palinologia dos Sedimentos Meso-Cenozóicos do Brasil (I). Boletim Técnico da Petrobrás, v. 17, n.3, p. 177-190, 1974a. 35. REGALI, M.S.P.; UESUGUEI,N.; \& SANTOS, A.S. Palinologia dos Sedimentos Meso-Cenozóicos do Brasil (II). Boletim Técnico da Petrobrás, v. 17, n.4, p. 263-301, 1974b. 36. SILVA, S.A.F. Palinologia do Neógeno da Bacia do Alto Solimões, Amazônia Ocidental, Brasil: Aspectos Sistemáticos, Bioestratigráficos e Paleoecológicos. Manaus, 2008, 182p. Tese (Doutorado em Biologia Tropical e Recursos Naturais da Amazônia) - Instituto Nacional de Pesquisas da Amazônia, INPA.

37. SILVA-CAMINHA, S.A.F.da.; JARAMILLO, C.A. \& ABSY, M.L. Neogene palynology of the Solimões Basin, Brazilian Amazônia. Palaeontographica Abteilung B, v. 283, p. 1-67, 2010.

38. SILVA, W.G.; SOUZA, P.A. \& ARAI, M. Palinomorfos Neógenos do Poço 2-CA-1-RS, Bacia de Pelotas, Brasil: Significado Bioestratigráfico e Paleoecológico. Revista do Instituto de Geociências USP, 11:149-169, 2011.

39. SILVEIRA, R.R. Cronoestratigrafia e Interpretação Paleoambiental de Depósitos Miocenos da Formação Solimões, Região de Coari, AM. Manaus, 2005, 115p. Dissertação (Mestrado em Geologia Regional) - Instituto de Ciências Exatas, Universidade Federal do Amazonas.

40. SILVEIRA, R.R. Bioestratigrafia e Paleoecologia de Depósitos Neógenos e Pleistocenos Aflorantes na Porção Central e Ocidental da Bacia do Solimões, Estado do Amazonas, Brasil. Porto Alegre, 2015, 264p. Tese (Doutorado em Geociência) - Instituto de Geociências, Universidade Federal do Rio Grande do Sul).

41. SILVEIRA, R.R. \& NOGUEIRA, A.C.R. Palinoestratigrafia da Formação Solimões (Neógeno), Região de Coari, Amazonas. In: SIMPÓSIO DE PALEOBOTÂNICA E PALINOLOGIA, 12, Florianópolis. Boletim de Resumos...Florianópolis, p.204, 2008.

42. SILVEIRA, R. R. \& NOGUEIRA, A.C.R. Cronoestratigrafia de Depósitos Miocenos da Bacia do Solimões e sua correlação com depósitos da Amazônia.In: CONGRESSO BRASILEIRO DO QUATERNÁRIO, Belém. Resumos expandidos...Belém: Associação Brasileira de Estudos do Quaternário, 2007, CDRom.
43. SILVEIRA, R. R. \& SOUZA, P. A. Palinologia (esporos de fungo e pteridófitas, grãos de pólen de gimnospermas, cistos de algas e escolecodonte) das formações Solimões e Içá (Neógeno e Pleistoceno, Bacia do Solimões), Amazonas, Brasil. Pesquisas em Geociências, vol. 43, n. 1, p. 17-39, 2016.

44. SILVEIRA, R.R. \& SOUZA, P.A. Palinologia (grãos de pólen de angiospermas) das formações Solimões e Içá (bacia do Solimões), nas regiões de Coari e Alto Solimões, Amazonas. Revista Brasileira de Paleontologia, v.18, n.3, p. 455-474, 2015.

45. SOARES, E.A.A.; DINO, R.; SOARES, D.P.; ANTONIILI, L. \& SILVA, M.A.L. New sedimentological and palynological data from surface Miocene strata in the central Amazonas Basin área. Brazilian Journal of Geology, 45, n.3, p. 337-357, 2015. 46. VEGA, A.M.L. Reconstituição Paleoambiental dos Depósitos Miocenos na Região Centro Oriental da Bacia do Solimões. Manaus, 2006, 92p. Dissertação (Mestrado em Geologia Regional) - Instituto de Ciências Exatas, Universidade Federal do Amazonas.

47. VONHOF, H.B.; WESSELINGH, F.P. \& GANSSEN, G.M. Reconstruction of the Miocene western Amazonian aquatic system using molluscan isotopic signatures. Palaeogeography, Palaeoclimatology, Palaeoecology, v. 141, p. 85-93, 1998

48. WANDERLEY FILHO, J.R.; EIRAS, J.F. \& VAZ, P.T. Bacia do Solimões. Boletim de Geociências Petrobras, v.15, n.2.p.217-225, 2007.

49. WESSELINGH, F.P.; RÄSÄNEN, M.E.; IRION, G.; VONHOF H.B.; RENEME, W.; ROMERO PITTMAN, L. \& GINGRAS, M. Lake Pebas: a palaeoecological reconstruction of a Miocene, long-lived lake complex in western Amazonia. Cainozoic Research, 1(1-2):35-81, 2002.

50. WESSELINGH, F.P. \& RAMOS, M.I.F. Amazonian aquatic invertebrate fauna (Mollusca, Ostracoda) and their development over the past 30 millions years. In: HOORN, C. \& WESSELINGH, F.P. (Coordenadores). Amazônia: landscape and species evolution - A look into the past. USA, Blackwell Publishig Ltd. p. 302-316, 2010.

Manuscrito recebido em: 05 de Julho de 2016 Revisado e Aceito em: 06 de Setembro de 2016 
Apêndice 1. Palinomorfos registrados na Formação Solimões, região de Atalaia do Norte e Tabatinga, Amazonas.

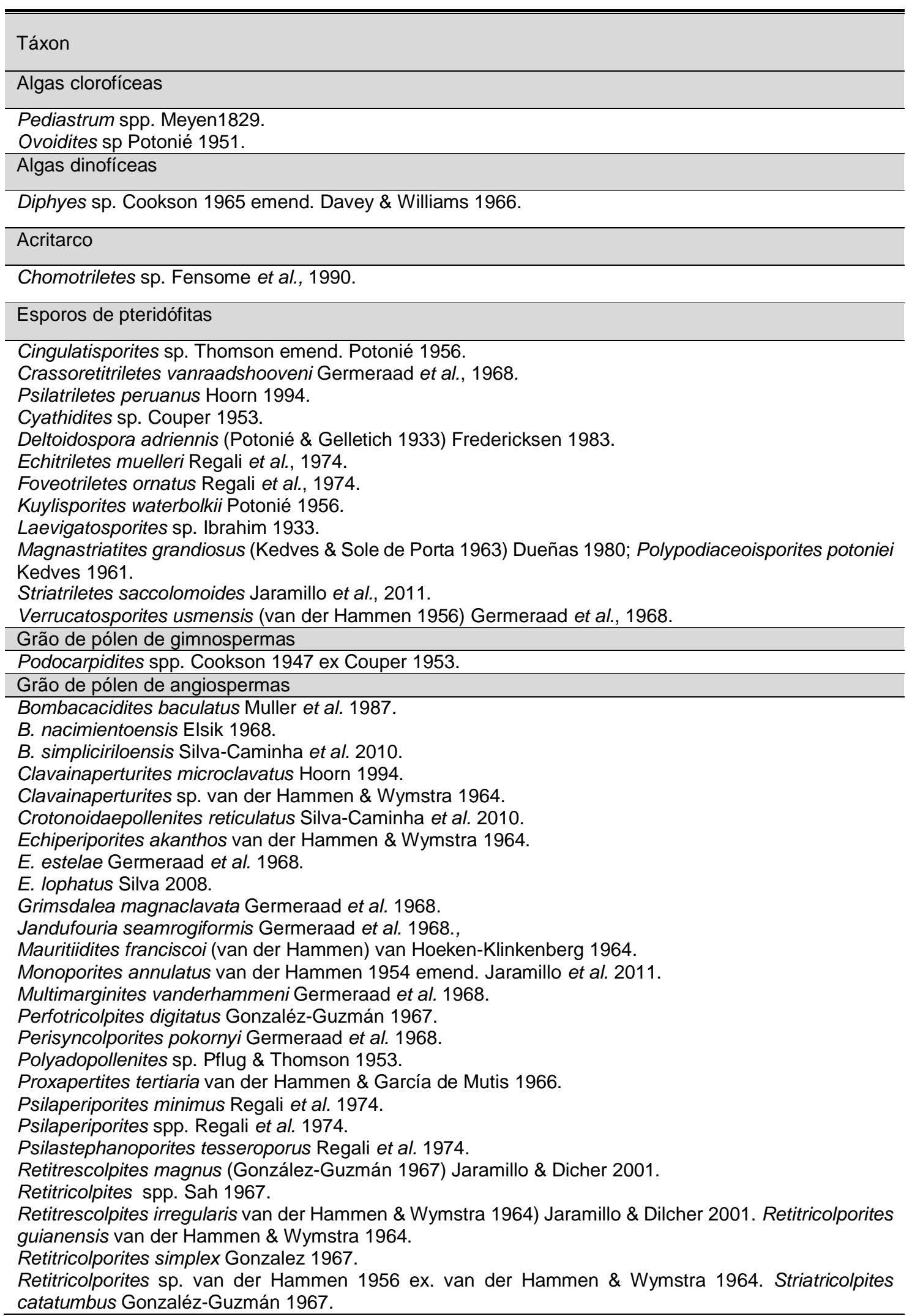

